\title{
José Barbosa de Almeida, Advogado e Professor de Direito.
}

\begin{abstract}
A Congregąção de Professôres desta Faculdade reuniu-se em sessão solene, no salão nobre, aos 4 de junho do corrente ano, prestando homenagem póstuma ao Prof. Dr. José Barbosa de Almeida, no trigésimo dia de seu falecimento.

Em nome dos Professôres, o Dr. Oscar Barreto Filho relembrando a personalidade do ilustre mestre, exaltou-lhe as qualidades de caráter, suas atividades culturais e docentes, em discurso publicado a seguir.
\end{abstract}

"Manda a tradição que, no trigésimo dia do passamento de um professor, se reuna o corpo acadêmico, na atmosfera ainda impregnada de mágoa pela perda sofrida, para prestar o preito derradeiro de afeto e de saudade ao mestre desaparecido.

Nesta piedosa evocação da vida e da obra de José Barbosa de Almeida, torna-se difícil condensar em breves palavras a personalidade, tão rica de conteúdo e de calor, do professor de Direito, do advogado e principalmente do homem. Mas é recorrendo justamente à compreensão humana, que sempre caracterizou o saudoso homenageado, que peço venia para recordar os traços marcantes da pessôa do Professor José Barbosa de Almeida, dentro de minhas limitações, escudado que estou tão sòmente na justificativa da amizade com que me honrou.

Durante dezenove anos desfrutei o convívio amável de José Barbosa de Almeida, desde quando fui por êle pro- 
posto para membro do Instituto dos Advogados de São Paulo, então sob a presidência do Professor Paulo Barbosa de Campos Filho. Nas reuniões do Instituto, nos Congressos jurídicos de que participamos, nos intervalos das aulas da Faculdade, nos fugazes contactos propiciados pela febricitante vida paulistana, tive ensejo de conhecer alguns aspectos de sua personalidade.

Foi, contudo, ùltimamente, que surgiu para mim a oportunidade de melhor avaliar, de modo abrangente, as múltiplas facetas que conferiam brilho e riqueza ímpares ao seu caráter adamantino.

10 de fevereiro de 1968. Decola do Aeroporto do Galeão, no Rio de Janeiro, o avião que conduziria para New York a missão de dez professôres da Faculdade de Direito de São Paulo que, a convite do Govêrno norteamericano, deveriam observar nas Universidades da grande nação os métodos, processos e técnicas utilizados no ensino do Direito, e verificar a possibilidade de aproveitar parte da experiência americana na renovação de nossos cursos jurídicos.

Já na viagem de ida, revelou o Professor José Barbosa de Almeida aos seus colegas o grande esfôrço que vinha há anos dispendendo, para intensificar o diminuto intercâmbio cultural entre o Brasil e os Estados Unidos, no campo da educação jurídica, em vivo contraste com o que ocorre em outros setôres da ciência e das artes. Êsse profundo interêsse pelos problemas da metodologia do ensino jurídico descobria apenas um dos ângulos da preocupação constante do Professor José Barbosa de Almeida, pelos problemas sociais que afligem a humanidade perturbada de nossos dias. Esse interêsse e essa preocupação indicaram de logo a afinidade entre o seu espírito e o meu, e serviram para consolidar durante a viagem a amizade, tão bruscamente interrompida pela evidência inarredável da morte. 


\section{A Vida.}

13 de abril de 1907. Nasce na cidade de São Paulo o menino José, primogênito do casal do Doutor Joaquim Barbosa de Almeida e Dona Amelia Fagundes Barbosa de Almeida.

Desde o início de sua vida, ainda no lar paterno, recebeu o menino e depois o adolescente José a influência decisiva que haveria de orientá-lo para as letras jurídicas, pois seu Pai, depois de brilhante carreira no Ministério Público e na magistratura de primeira instância, ascendeu à culminância da desembargadoria no Tribunal de Justiça de São Paulo.

Não lhe faltou, também, no aconchêgo do carinho materno, o ambiente propício ao aprimoramento das qualidades inatas de bondade, desprendimento e fina sensibilidade que marcaram indelèvelmente o seu caráter.

Outro fator que não pode ser olvidado na formação da personalidade de José Barbosa de Almeida é o do meio em que passou a sua infância, nas pitorescas cidades de São Pedro de Piracicaba e, principalmente, Santo Antonio da Cachoeira, hoje Piracaia, encastoada nas faldas da serrania da Mantiqueira, onde seu Pai foi promotor público e depois juiz de direito.

Aquêle meio simples e ingênuo de Piracaia, em que se desenrolaram os descuidosos folguedos da meninice e da adolescência, também contribuíu para desenvolver no jovem a espontaneidade, o senso de solidariedade, a consciência social que foram apanágios de seu feitio moral. Nas preces formuladas com o falar característico dos caboclos, nas procissões da Semana Santa, nas ladainhas do mês de Maria, nas álacres e ruidosas festas juninas, nas congadas de Natal, que impregnavam de misticismo a pacata cidadezinha, encontrou o pequeno José as bases sólidas da formação religiosa e do apêgo às sadias tradi- 
ções da velha grei paulista, que o acompanhariam vida afora.

O menino buliçoso de Piracaia continuou no homem maduro, tão certo é, no verso do poeta do Paraiso Reconquistado, que

"The childhood shows the man,

As morning shows the day"

(John Milton, Paradise Regained)

Terminados os estudos preparatórios, efetuados nos Colégios São Bento e Arquidiocesano, em 1924, com apenas 16 anos, definiu José Barbosa de Almeida a sua vocação jurídica, ingressando na Academia de Direito do Largo de São Francisco.

Quê coisas devem ser relembradas, nessa quadra amorável da vida, quando tudo são esperanças e ilusões? Não é preciso fazê-lo, pois todos nós, acadêmicos de ontem e de sempre, nos recordamos com saudade dêsse período em que iniciamos o diálogo fremente com a vida. Para o Barbosinha, como o chamavam afetuosamente os colegas, estudante pobre e esforçado, como para Fagundes Varela, a vida poderia ter os momentos de aspereza,

"Mas tinha o nome inscrito entre os alunos

Da escola de São Paulo - e é o quanto basta"

Nessa idade, em que o intelecto sobrepõe-se ao todo psíquico, ainda assim observa-se no moço José a consciência social, nota afetivo-volitiva dominante na sua individualidade. E o Barbosinha, não obstante a necessidade de arranjar meios de aumentar a mesada insuficiente, aceita a designação para comissário de menores, feita pelo ínclito Dr. Firmino Whitaker, então juiz de menores da Capital, exercendo a função sem nenhuma remuneração.

Ainda estudante, foi o moço Barbosa, por algum tempo, reporter das Folhas, o que lhe ensejou maior contacto com 
as realidades e misérias da vida qüotidiana numa grande cidade como São Paulo.

No tempo de estudante, morou José Barbosa de Almeida com seu tio Padre Péricles Gomes Barbosa, o lembrado Padre Péricles, em cujo exemplo encontrou mais elementos para fortalecer a sua natural inclinação para a caridade e a solidariedade cristãs. Imbuído de grande fôrça de vontade, encontrava ainda nessa época o Barbosinha vagar para, depois de cumprir seus deveres, auxiliar os colegas no desempenho das tarefas escolares, como testemunhou há poucos dias o Dr. Francisco Assunção Ladeira.

A convivência com o Padre Péricles avivou e fortificou no moço José a convicção católica. Dotado de profundo sentimento de religiosidade, ingressou depois na Irmandade da Ordem Terceira do Carmo, cumprindo com acendrado fervor suas obrigações e encargos.

Para êle, a prática da religião correspondia à satisfação de um anseio íntimo, sem a preocupação de exteriorizálo ou de fazer proselitismo. Estava sempre pronto a atender ao apêlo da caridade, prestando serviços gratuitos sempre que solicitados por entidades filantrópicas, como fêz durante largos anos com a Liga das Senhoras Católicas. A intensidade de sua convicção religgiosa é denotada pela circunstância de que baixou à campa envolto no hábito da Irmandade que em vida tanto amou.

A solenidade da colação de grau de bacharel em ciências jurídicas e sociais da turma de 1928, a que pertencia José Barbosa de Almeida, deu-se no dia 24 de dezembro. véspera de Natal.

Na tarde dêsse dia engalanou-se o salão nobre do velho casarão de taipa da Academia, para a sessão solene de formatura, presidida pelo Vice-Diretor, Doutor José de Alcantara Machado d'Oliveira no impedimento do Diretor, o Doutor Antonio Januario Pinto Ferraz, na presença dos 
professôres João Braz de Oliveira Arruda, Rafael Corrêa de Sampaio, Teófilo Benedito de Souza Carvalho, José Joaquim Cardoso de Mello Neto, Braz de Souza Arruda, Vicente Ráo e Waldemar Martins Ferreira, livre-docente Gabriel José Rodrigues de Rezende Filho e secretário Julio Joaquim Gonçalves Maia.

Foi orador da turma o bacharelando Renato Soares de Toledo e paraninfo o Professor Cardoso de Melo Neto, que proferiu a alocução alusiva ao ato. Faziam parte da turma, dentre outros, os bacharelandos Alberto de Siqueira Reis, José Pinto Antunes, Laurindo Dias Minhoto Junior, Manoel Thomaz Carvalhal, Alberto Byington Junior, José Ignacio Benevides de Rezende, Lauro Celidonio Gomes dos Reis, Paschoal Imperatriz, Paulo Teixeira de Camargo, Raphael Ribeiro da Silva, Linneu Prestes, Caio Prado Junior, Joaquim de Sylos Cintra, José Antonio Arantes Monteiro, Cid de Almeida Franco, além de Antonio Ferreira Cesarino Junior e Basileu Garcia, que colaram grau no ano seguinte, por terem sido obrigados a interromper os estudos. Como se vê, foi uma turma luzida, embora pequena, composta de nomes que se destacaram por variadas formas no cenário jurídico brasileiro.

Formado em Direito, cursou ainda José Barbosa de Almeida a Faculdade de Filosofia e Letras do Mosteiro de São Bento, então agregada à Universidade de Louvain (Bélgica).

Armado cavaleiro do Direito, com 21 anos de idade, desde logo iniciou-se Barbosa de Almeida na advocacía militante, em Piracaia, de que foi Prefeito Municipal no biênio 1929/30. Na sua gestão, promoveu o calçamento da cidade e realizou vários melhoramentos públicos. Voltando para São Paulo, estagiou na Procuradoria Geral do Estado, servindo junto aos procuradores gerais Desembargadores Costa Manso e Manoel Carlos, abrindo escritório de advocacia, juntamente com o Dr. Decio Toledo Leite.

Em 6 de setembro de 1930, contraíu matrimônio com D. Maria José Leopoldo e Silva Barbosa de Almeida, des- 
cendente de velho tronco paulista, sobrinha do Arcebispo Dom Duarte Leopoldo e Silva. No seu lar ditoso, encontrou o Professor Barbosa de Almeida motivos de inspiração e de ânimo para a luta qüotidiana, de início na pessôa de sua querida Maria José, companheira extremosa de todos os momentos, e depois nos seis filhos e onze netos que abençoaram o feliz enlace.

A sua dedicação à família sempre se patenteou de modo irretorquível, inclusive em relação aos irmãos, a que assistiu e orientou. Quem nos falou disso, no próprio dia do entêrro, com a voz embargada por irreprimível emoção, foi o Dr. Sebastião Barbosa de Almeida, que se referiu ao irmão mais velho como personificando um verdadeiro segundo Pai.

Desambicioso de bens materiais, esforçava-se no entanto o Professor Barbosa de Almeida por assegurar o bem estar da família, e uma de suas aspirações maiores era a de enviar os filhos completar os estudos no estrangeiro, de modo a ampliar-lhes os horizontes e a visão global da vida.

Falando de José Barbosa de Almeida numa escola de moços, não posso deixar de referir-me à compreensão que manifestava para com os homens em geral, e especialmente para com a juventude. Aceitava êle as pessôas como são, sem delas exigir só qualidades, pois os defeitos dos homens fazem parte de sua humana condição.

Procurando sondar as causas da inquietação dos jovens, José Barbosa de Almeida valorizava seus propósitos e suas ações, com carinho motivado por uma complacência paternal. Podiam os jovens, certamente, contar com sua compreensão e bôa vontade.

Eu mesmo, como os demais companheiros da recente viagem, posso testemunhar os cuidados demonstrados por Josė Barbosa pelos seus familiares. Era o maior amigo do filho Marcelo, seu companheiro constante de passeios, viagens e estudos; compartilhava seus anseios e o ajudava 
a vencer a quadra difícil em que o adolescente se faz homem.

\section{A Obra.}

Frutuosa foi a vida de José Barbosa de Almeida, na advocacía e no magistério do Direito.

No exercício da profissão, que dignificou por quasi quarenta anos, procurou servir ao bem comum, com o mais alto espírito de solidariedade humana. Não titubeou, muitas vêzes com prejuízo de interêsses materiais, em dedicar-se à defesa de causas dos desprotegidos da fortuna.

Não se esqueceu José Barbosa de Almeida de que o nome de advogado se refere a um pedido de ajuda: ad-vocatus; porisso a tarefa do advogado, antes de ser técnica, se desenvolve principalmente no campo moral.

Na conclusão do livro sôbre A Criação do Direito, lembra o Professor Goffredo Telles Junior que Petrazycki, numa de suas primeiras obras, demonstrou que o direito autêntico é uma expressão de amor. E conclui: $O$ certo é que o direito, como o amor, tem a sua fonte originária no coração dos homens.

Esse conceito se aplica, à maravilha, à vida de José Barbosa de Almeida, que foi um grande advogado porque, para êle, o direito estava no mais profundo do coração.

A consciência social de José Barbosa de Almeida manifestou-se pela desinteressada colaboração que durante muitos anos prestou ao Instituto de Direito Social (de que foi fundador, sócio titular e conselheiro) e ao Institūto Cultural do Trabalho (de que foi Presidente, desde a fundação em 1963).

A sua sensibilidade de católico praticante sempre o predispôs a uma palavra amiga aos necessitados, levandolhes o remédio jurídico, econômico e educacional de que tanto precisam. 
Sua ação benfazeja no campo social desenvolveu-se notadamente no Instituto Cultural do Trabalho, entidade cujo objetivo é a formação cultural e técnica dos trabalhadores, em moldes democráticos e mediante cursos permanentes ou intensivos, seminários e conferências, em todo o território nacional, inclusive para o exercício da liderança visando a harmonia entre o capital e o trabalho, o desenvolvimento da economia nacional e melhores condições sociais.

À concretização desta iniciativa, como a todos os apêlos que lhe fôssem dirigidos para o trabalho no campo social, nunca soube negar sua ajuda e cooperação.

Convencido da relevante missão social que cabe ao jurista desempenhar no mundo contemporâneo, o advogado José Barbosa de Almeida seguiu à risca os preceitos éticos tão bem sintetizados pelo Professor Miguel Reale, em trabalho apresentado à $2 .{ }^{\mathrm{a}}$ Conferência Nacional da Ordem dos Advogados do Brasil, reunida em São Paulo de 4 a 11 de agôsto de 1960:

"O advogado deve preservar, contra tudo e contra todos, o cunho liberal e humanista de sua profissão; liberal, porque fundada na liberdade de convicção científica; humanística, porque tem como fundamento a dignidade da pessoa humana e a livre afirmação das infinitas tendências e inclinações do homem.

O advogado deve, acima de tudo, capacitar-se de que a sua profissão não se exaure no círculo restrito de interêsses pessoais, mas constitui um elemento substancial da comunidade concreta dos homens que trabalham e realizam os valores sociais."

$\mathrm{Na}$ defesa dos valores sociais e espirituais do cristianismo, da liberdade e do humanismo, ligou o Professor 
José Barbosa de Almeida o seu nome, de modo imperecível, à história dos órgãos de classe dos advogados.

Foi membro do Conselho da Ordem dos Advogados do Brasil (Secção de São Paulo) e do Tribunal de Ética Profissional de São Paulo.

Membro do Instituto dos Advogados de São Paulo, desde 1936, foi $1 .^{\circ}$ Secretário na gestão Paulo Barbosa de Campos Filho, em 1947, e 1..$^{\circ}$ Vice-Presidente no último mandato Alcides da Costa Vidigal, em 1951. A seguir, foi $21 .^{\circ}$ Presidente substituto, em 1952, e 22. ${ }^{\circ}$ Presidente eleito para o biênio 1953/1955, e reeleito sucessivamente com mandato até 1966. Presidente nato, em virtude do novo Estatuto aprovado em 1964, ao fim da gestão recebeu a medalha "Ao mérito".

De sua atuação na Casa de Francisco Morato, quem dá contas é o infatigável cronista da gente do Fôro, o Dr. João Gualberto de Oliveira; ei-las :

“A partir de $10^{\circ}$ de abril de 1952 - há portanto mais de catorze anos consecutivos - o sodalício teve como figura de proa o vulto exponencial de José Barbosa de Almeida, que, com seu fino tacto e superior critério, tão bem soube acomodar as diversas correntes de pensamento que cruzam o céu no microcosmo jurídico paulista. Em virtude do elegante "savoir faire" de seu operoso Presidente, o Instituto dos Advogados de São Paulo, que poderia ser talvez arena onde se chocassem em renhidos prélios os gládios das opiniões colidentes, é casa de paz, ordem e trabalho profícuo, um dos mais seguros redutos de camaradagem, de satisfação e bem-estar para os profissionais a êle filiados."

Essas qualidades de ponderação e de equilíbrio, José Barbosa de Almeida também as demonstrou na sua rápida passagem pela magistratura, como juiz federal suplente da Secção de São Paulo, havendo exercido a judicatura plena nos anos de 1936 e 1937; e como juiz efetivo, da classe dos juristas, do Tribunal Regional Eleitoral de São Paulo. 
Enquanto juiz, sempre manteve uma atitude de compreensão e de aprêço pela nobre função do advogado.

O tirocínio da advocacia, o saber da experiência feito, com o passar dos anos conduziu naturalmente José Barbosa de Almeida à concretização da aspiração máxima do jurista: - o magistério do Direito!

Com a fundação da Faculdade de Direito da Universidade Mackenzie, em 1956, é contratado para exercer a função de Professor de Direito Comercial e posteriormente de Ciência das Finanças.

Mas o ideal supremo de José Barbosa de Almeida o retôrno à alma mater na qualidade de professor - é atingido em 1964, quando presta concurso e, aprovado, recebe o grau de doutor em Direito e é nomeado Livre-Docente de Ciência das Finanças da Faculdade de Direito da Universidade de São Paulo.

Para inscrição no concurso, apresentou a tese Orçamento e Política Fiscal, tendo sido argüido pela Comissão Examinadora integrada pelos Professôres E'nesto Leme, Antonio Ferreira Cesarino Junior, Teotônio Monteiro de Barros Filho, José Pinto Antunes e Sílvio Rodrigues.

No seu trabalho, parte o Professor José Barbosa de Almeida da premissa de que: - "o objetivo da Política Fiscal é concorrer para a realização dos fins supremos do Estado - o bem comum e a justiça social. Mas - advirtase - realizá-los segundo a concepção de Estado que afirme o primado do Homem e lhe assegure os direitos e as liberdades essenciais conquistadas a duras penas no correr dos séculos."

"Entretanto, nem sempre os clássicos e tradicionais instrumentos de Política Fiscal são hábeis para o preenchimento daqueles fins. Por outro lado, os novos instrumentos, as modernas técnicas, não atendem exigências que o regime democrático impõe aos gestores dos dinheiros públicos no tocante à fiscalização e à responsabilidade pelo seu emprêgo." 
"A experiência brasileira denota, ademais disso, uma tremenda concentração de poderes e de dinheiro nas mãos da União Federal, ameaçando destruir o federalismo e coartando a iniciativa privada."

"Êstes fatos nos levam a concluir que é necessária $e$ urgente a reformulação do processo de fiscalização $e$ tomada de contas, de modo a propiciar a flexibilidade $e$ rapidez que são condições de êxito para a Política Fiscal."

Como Livre-Docente, o Professor Barbosa de Almeida teve ensejo de reger cursos de Direito Comercial e de Direito Civil, e no ano passado foi nomeado Professor Catedrático substituto de Ciência das Finanças.

No magistério, apresentava os requisitos do bom professor: - gostava da matéria e dos alunos; conhecia e compreendia os estudantes, aos quais tratava com bondade.

Ültimamente, vinha trabalhando com afinco, nos vagares de suas múltiplas ocupações, a fim de renovar e atualizar os seus conhecimentos de Finanças Públicas, especialidade a que se dedicara. Nas bibliotecas das Universidades e nas livrarias, nas resenhas e nos catálogos, procurava informar-se de tôdas as novidades da matéria, com o maior cuidado e atenção.

Além da tese de concurso, deixou publicados os seguintes estudos: - Disciplina do Capital Estrangeiro e da Remessa de Lucros na Legislação Brasileira (para o volume "in memoriam" de Tulio Ascarelli), Cláusula "rebus sic stantibus" e Imprevisão, Contratos Diferenciais e Vendas a Têrmo, Reclamação reivindicatória em Concordata Preventiva.

As atividades culturais e docentes do Professor José Barbosa de Almeida não se limitaram ao âmbito pátrio, pois participou ativamente de vários órgãos e entidades internacionais e de numerosos certames realizados no estrangeiro. 
Assim é que foi Presidente efetivo da Federação Interamericana de Advogados (Inter-American Bar Association) no período 1953/1954. Nessa qualidade, presidiu a VIII Conferência Interamericana de Advogados reunida em São Paulo, em 1954, como parte integrante das festividades comemorativas do IV Centenário de fundação da cidade.

$\mathrm{Na}$ sessão solene de instalação, havida no dia $15 \mathrm{de}$ março de 1954 neste mesmo salão nobre, o Dr. José Barbosa de Almeida proferiu o discurso inaugural, evocando a passagem de uma das epístolas, na qual o Apóstolo São Paulo nos adverte que devemos viver segundo a lei. A advertência, conquanto se refira mais diretamente à lei espiritual e à lei moral, alcança também a lei jurídica. E prosseguiu dizendo:

"Aspiramos a um ordenamento jurídico que corresponda exatamente à consciência social, que satisfaça plenamente os interêsses espirituais e materiais, tanto dos indivíduos como da sociedade".

" $E$ bem verdade que o homem que domina a Natureza e condiciona suas fôrças ainda não encontrou o caminho para vencer-se a si mesmo. Talvez por isso nem a lei divina, nem o direito positivo, lograram fazer melhores os homens."

"Todavia, está ao nosso alcance orientar a legislação num determinado sentido. Por certo as conclusões que se estabelecerem nesta Conferência hão de reforçar o estatuto jurídico que levará os indivíduos e as Nações aos seus verdadeiros e legítimos fins, servindo-lhes de apôio exterior, de refúgio, de proteção eficiente; estatuto cuja função não seja a de dominar, mas a de servir, a de desenvolver e fortificar a vitalidade social, provendo as necessidades da vida com as suas exigências cambiantes, dirigindo-as para o aperfeiçoamento de tôdas as energias em função do bem comum e da paz universal."

"É prerrogativa e missão do Estado regular, vigiar e auxiliar as atividades particulares e individuais, fazendo-as 
convergir harmoniosamente para o bem comum, isento de concepções arbitrárias e marcado pelo primado do espírito sôbre a matéria."

Essa verdadeira carta de princípios contém a súmula dos ideais por que em vida batalhou e lutou José Barbosa de Almeida.

Não param aí as atividades e trabalhos do Professor Barbosa de Almeida, cujo ânimo infatigável não se atemorizava com a quantidade e a extensão dos encargos.

No país, vêmo-lo desempenhar as funções de membro da Comissão Executiva do IV Centenário da cidade de São Paulo. Conselheiro do Instituto de Cultura Hispânica de São Paulo. Membro do Conselho Jurídico da Associação Comercial de São Paulo. Membro do Conselho Técnico de Economia, Sociologia e Politica da Federação do Comércio do Estado de São Paulo. Conselheiro da Associação dos Advogados de São Paulo. Membro do Conselho Diretor do Instituto Brasileiro de Direito Comercial Comparado e Biblioteca "Tullio Ascarelli".

No exterior, exerceu as funções de membro do "Board of Trustees" do Instituto Americano para o Desenvolvimento do Sindicalismo Livre", com séde em Washington. Foi membro das seguintes entidades: "Societé de Legislation Comparée", de Paris; "Association Henri Capitant pour la Culture Juridique Française", de Paris; "Societé Internationale de Droit du Travail et de la Securité Sociale", de Bruxelas.

Pertenceu, em diferentes épocas, a diversas comissões para reforma da legislação, especialmente no tocante a processo e organização judiciária. Participou de numerosos congressos e conferências jurídicas, no país e no estrangeiro. Deu curso sôbre Títulos de Crédito no Direito Comparado Interamericano, no Seminário Interamericano para jovens advogados, realizado sob os auspícios da Federação Interamericana de Advogados em Curitiba, em julho de 1961. Tratou do tema: - Negociações Tarifárias: pro- 
cedimentos para concessões aduaneiras - Relação dos países da Associaçấo Latino Americana de Livre Comércio (ALALC) com The General Agreement in Tariffs and Trade (GATT)", no Seminário sôbre Aspectos jurídicos da $A L A L C$, realizado em Montevidéo, Uruguai, em novembro de 1963, sob os auspícios do Banco Interamericano de Desenvolvimento e da Federação Interamericana de Advogados.

Tal foi a mole de trabalhos feitos por José Barbosa de Almeida, que sòmente uma grande fôrça de vontade aliada a uma extraordinária pertinácia, ocultas sob semblante tão sereno, podem explicar sua realização.

O ideal cuja concretização por último preocupou o espírito do Professor José Barbosa de Almeida foi o da renovação do ensino jurídico em nosso país, visando à melhor integração do estudante na Universidade e da própria escola na sociedade.

É bem conhecido o esfôrço desenvolvido pelo saudoso mestre, em colaboração com uma valorosa equipe de professôres desta Casa, para a instalação de um Instituto de Ciências Políticas e de outro Instituto de Direito Econômico e Financeiro.

Nessa ordem de idéias, propugnou também o Professor Barbosa de Almeida pela adoção de novos métodos de educação jurídica, cooperando eficazmente nos entendimentos para a ida, aos Estados Unidos da América, da missão de professôres a que de início me referi.

\section{Senhores :}

Tão intensamente viveu José Barbosa de Almeida sua vida afanosa na busca do ideal, que certamente não teve tempo para meditar sôbre si mesmo.

Nós, porém, seus familiares e amigos, evocando a suave lembrança das coisas passadas, temos bem presente o conhecido pensamento de Alfred de Vigny: 
"Uma grande vida é um ideal da juventude realizado na idade madura".

$\mathrm{E}$ verificamos que o moço de ôntem sempre teve a impulsioná-lo para a frente a sua fé na dignidade da pessoa humana, a sua fé na liberdade imperecível, a sua fé no livre comércio de homens e idéias, a sua fé inquebrantável em Deus onipotente.

$\mathrm{E}$ reconhecemos, comovidos, que foi uma grande vida a de José Barbosa de Almeida, porque o homem maduro realizou plenamente os ideais fagueiros da juventude.

4 de maio de 1968, dia de Santa Mônica, mãe de Santo Agostinho, doutor da Igreja.

Aprestava-se mais uma vez o Professor José Barbosa de Almeida para tomar o avião das 21 horas, que o levaria aos Estados Unidos da América, no cumprimento de várias missões de natureza educativa e cultural.

Deus, porém, nos seus altos desígnios, quis premiar aquêle espírito animoso e forte, libertando-o das canseiras e atribulações da vida material.

E nesse dia, às 19 horas, José Barbosa de Almeida alçou célere o vôo derradeiro para a eternidade"

\title{
Discurso de Agradecimento.
}

\author{
Após as palavras do Dr. Oscar Barreto Filho, \\ falou, agradecerdo em nome da família, o Dr. José \\ Duarte Barbosa de Almeida.
}

"Coube-me a honra, como filho mais velho, de formular, em nome da família de José Barbosa de Almeida, à egrégia congregação da Faculdade de Direito da Universidade de São Paulo, os mais sinceros agradecimentos pela homenagem que lhe é tributada ao completar-se um mês de seu falecimento.

Após a realização da Santa Missa, em que todos nós elevamos a Deus Nosso Senhor as mais fervorosas preces 
pela sua alma, quis também a Congregação da Faculdade, nesta sessão solene, dar mais uma demonstração do quanto de estima tributou a José Barbosa de Almeida.

Depois de ouvirmos as palavras pronunciadas pelo douto Professor Oscar Barreto Filho desejamos expressar, com o nosso sentimento de gratidão, quão significativa é para todos nós esta tocante homenagem.

Bem sabemos não ser comum reunir-se a Congregação desta Faculdade em sessões solenes, senão para acontecimentos da mais alta relevância. Tendo portanto se decidido realizar esta sessão de caráter solene, só podemos interpretá-la como a manifestação do mais elevado apreço à sua memória.

Êste acontecimento tem para nós um significado relevante, embora as condições em que se realiza nos faça rememorar aquêle infausto dia em que perdemos o nosso pai e melhor amigo.

E a Faculdade de Direito da Universidade de São Paulo que interrompe suas aulas para homenagear um de seus professôres. É a velha academia do Largo de São Francisco, cujas tradições êle tanto venerou, que abre suas portas para receber os familiares e amigos do seu antigo aluno e professor.

Essa mesma Academia que foi sempre, em todos os tempos, a escola de civismo, que deu ao Brasil eminentes homens públicos, notáveis diplomatas, renomados juristas e brilhantes advogados, foi essa mesma Academia que acolheu no verdor dos 16 anos um jovem que se tornou um autêntico advogado, realizando as suas mais elevadas aspirações.

Guiado pelos exemplos de seu pai e pelos conselhos de sua mãe, êle se dedicou dé corpo e alma ao estudo do direito, fazendo dest'arte o curso que o preparou para os próximos embates das lutas forenses. Seus mestres também muito contribuiram para que seu entusiasmo e dedicação ao estudo do direito não se limitasse ao periodo em 
que cursou esta Faculdade, pois jamais dela se desligou pelos afetivos laços de filial respeito e admiração.

Dedicando-se à advocacia com autêntica vocação sacerdotal, inspirado e animado por sua espôsa, e mercê da generosidade de seus colegas e amigos, pôde ocupar em sucessivas oportunidades lugares de destaque em entidades de natureza profissional, cooperando com o seu trabalho, sempre colocado em defesa dos lídimos e legítimos interêsses da classe, nos seus organismos mais representativos como o Consêlho da Ordem dos Advogados do Brasil, o Tribunal de Ética, a Associação dos Advogados de São Paulo, o Instituto de Direito Social, o Instituto dos Advogados de São Paulo, a Associação Interamericana de Advogados e a Federação Interamericana de Advogados.

Contudo para êle não bastou sentir-se realizado profissionalmente. Nunca lhe faltou uma vasta clientela com a qual pôde, embora sem a preocupação de auferir rendimentos vultosos, dar aos seus os meios necessários à subsistência da família e educação dos filhos.

Apaixonado cultor do Direito, acostumado ao trabalho e ao estudo até altas horas da madrugada, atingiu a uma das suas mais elevadas aspirações através do ingresso no Magistério nesta tradicional e querida Academia e na Faculdade de Direito da Universidade Mackenzie.

de justiça, portanto, que aqui se proclame o elevado aprêço com que êle sempre se referia a esta Faculdade, aos seus ilustres e cultos professôres, os quais com o calor da amizade e com os constantes ensinamentos lhe permitiram o convívio dos mais felizes e agradáveis de sua vida.

De tal sorte esta felicidade se evidenciou, que em suas manifestações junto a nós jamais escondia o seu orgulho em pertencer ao corpo docente da sua velha Academia se é que tal pode-se atribuir a quem primou pela modéstia em todos os atos e momentos de sua vida.

É de justiça também, que testemunhemos de público a sua conduta de filho exemplar, irmão dedicado, espôso virtuoso e pai amantíssimo, cujos exemplos continuarão a 
servir de roteiro às nossas existências e à nossa conduta. Tais exemplos não se cingiram a êste ou aquêle setôr, porquanto se dedicado foi ao trabalho desde a juventude, se até o último instante de sua vida ainda cuidava das coisas vinculadas às suas atividades profissionais, é mistér que ponha em destaque seus exemplos de um autêntico espôso, pai e chefe de família.

Não nos parece descabido neste momento em que se evoca a memória daquele que soube cultivar virtudes, dizer que êle jamais se apegou às paixões mundanas, nem fêz do amor próprio algo que pudesse afastá-lo dos ensinamentos do Evangelho e da sua fé na existência de Deus. Dest'arte formou-se um caráter vigoroso, onde a humildade tornou-se um atributo marcante, a caridade jamais foi esquecida porque através do cultivo dessas mesmas virtudes é que êle pôde estar sempre mais perto de Deus. Renunciando o melhor para si, em proveito de outrem, deu provas eloqüentes de desapêgo às coisas materiais, fazendo, muitas e muitas vêzes, sacrifícios acima de suas próprias fôrças para o bem estar daqueles que o cercavam.

A simplicidade era para êle uma forma de bem viver, bastando a companhia dos seus parentes e amigos para que a felicidade lhe fôsse completa.

Se alguma vez foi ferido injusta e desmerecidamente, embora magoado e com o coração contristado, soube perdoar cristãmente porque as lições do Evangelho sempre nortearam sua vida. Entendia que o perdoar engrandece, dignifica e até mesmo enaltece a quem perdoa.

Alguém disse que o homem deve cumprir o esfôrço de criar-se a si mesmo, tornando-se, portanto, o artífice do seu próprio destino. Criando-se a si mesmo, isto é procurando entender o sentido da vida e a razão de sua existência, está construindo o seu destino pois na vida tudo é ligado e correlato. Atado aos fatos oriundos do passado e às circunstâncias que vão surgindo e atuam na direção dos atos humanos, explica-se a obediência à lei de causalidade. Êstes conceitos são válidos, porque não subtraem o 
esfôrço, a dedicação, as virtudes, a formação moral e profissional daqueles a quem se diz que o destino reservou grandes coisas. A felicidade, por outro lado, está ìntimamente vinculada à conduta ou à direção que os sêres humanos imprimem à sua própria vida.

Aquêle que quis ser um dia advogado, aquêle que quis ir mais além, e tornar-se professor da Faculdade de Direito, conduziu para o atingimento de tão nobres e elevados objetivos todos os seus atos, aliados a muitas circunstâncias, e por isso viveu feliz, embora Deus tenha limitado a sua existência a um tempo demasiadamente curto.

Os momentos de adversidade, de dor são uma prova muito dura para nossa capacidade de resistência sentimental. Porém é na hora crucial do infortúnio, no dia aflitivo da dor, no tempo amargurado das tristezas, que mais se requer a fortaleza de ânimo. Os incompreensivos rebelamse contra a adversidade, não resistem à dor. Os compreensivos, por outro lado, submetem-se e resignadamente aceitam as vicissitudes adversas e procuram consolar-se para resistirem ao sofrimento. Encontram na vontade soberana de Deus a última palavra, a decisão final de que não cabe recurso, porque é uma sentença proferida pelo Supremo Juiz.

Consóla-ncs, a nós todos, especialmente à mamãe, manifestações como a presente promovida pelos colegas e amigos, neste sagrado recinto da Faculdade de Direito da Universidade de São Paulo, a velha e tradicional academia do Largo São Francisco a quem José Barbosa de Almeida tanto orgulho e amor soube devotar. 